\title{
Impact on Renal Function of Rosuvastatin Preload Prior to Elective Percutaneous Coronary Intervention in Chronic Statin Users
}

\author{
Mauricio Sales de Oliveira ${ }^{1}$, Kleber Bomfim Araujo Martins², J. Ribamar Costa Jr. ${ }^{3}$, Alexandre Abizaid ${ }^{4}$, \\ Jackson Stadler ${ }^{5}$ Luiz Alberto Mattos ${ }^{6}$, Daniel Chamié ${ }^{7}$, Dimytri Siqueira ${ }^{8}$, Ricardo Costa ${ }^{9}$, \\ Rodolfo Staico ${ }^{10}$, Fausto Feres ${ }^{11}$, Amanda G. M. R. Sousa ${ }^{12}$, J. Eduardo Sousa ${ }^{13}$
}

\begin{abstract}
Background: Contrast-induced nephropathy $(\mathrm{CIN})$ is a potential complication after percutaneous coronary intervention $(\mathrm{PCI})$. The pathogenesis of this complication has been linked to inflammation, endothelial dysfunction and oxidative stress. In this study, statins were investigated as a treatment for CIN because of the pleiotropic effects of these drugs, assessing whether a preload dose of rosuvastatin prior to elective PCI in patients receiving chronic statin treatment reduced the incidence of CIN. Methods: This study was designed as a prospective, randomised, open label, single-centre study. The patients were grouped based on the inclusion (group 1) or exclusion (group 2) of $40 \mathrm{mg}$ rosuvastatin treatment two to six hours prior to $\mathrm{PCl}$. The frequency of $\mathrm{CIN}$ in these two groups, as well as the diabetic and renal dysfunction subgroups, was compared. Results: The study comprised 135 patients aged $60.7 \pm 9.3$ years who were randomised to group $1(n=67)$ or group $2(n=68)$. The overall prevalence of diabetes was $31.1 \%$, and the overall prevalence of a creatinine clearance rate $<60 \mathrm{~mL} / \mathrm{min}$ was $13.3 \%$. The overall incidence of $\mathrm{CIN}$ was $8.1 \%$, with no difference between groups (9\% vs. $7.4 \%$; $\mathrm{P}=0.89)$. The incidence of $\mathrm{CIN}$ was $15 \%$ vs. $13.6 \%$ in the diabetic patients $(P=0.75)$, and $12.5 \%$ vs. $0 \%$ in those
\end{abstract}

\section{RESUMO}

Impacto na Função Renal de uma Dose
de Reforço de Rosuvastatina Prévia a Intervenção
Coronária Percutânea Eletiva nos Pacientes
em Uso Crônico de Estatina

Introdução: A nefropatia induzida pelo contraste (NIC) é uma complicação potencial após a intervenção coronária percutânea (ICP). A patogênese está associada a mecanismos inflamatórios, disfunção endotelial e estresse oxidativo, e as estatinas, por seus efeitos pleiotrópicos, vêm sendo analisadas nesse cenário. Avaliamos se uma dose de reforço de rosuvastatina pré-ICP eletiva, em pacientes em uso crônico de estatina, reduz a ocorrência de NIC. Métodos: Estudo prospectivo, randomizado, aberto, realizado em único centro. Os pacientes foram divididos de acordo com a utilização (grupo 1) ou não (grupo 2) de $40 \mathrm{mg}$ de rosuvastatina, 2 a 6 horas pré-ICP. A frequência de NIC foi comparada entre os dois grupos e nos subgrupos de diabéticos e com disfunção renal prévia. Resultados: Foram incluídos 135 pacientes, com idade de 60,7 \pm 9,3 anos, randomizados para o grupo $1(\mathrm{n}=67)$ ou para o grupo $2(\mathrm{n}=$ 68). A prevalência de diabetes foi de $31,1 \%$ e de clearance de creatinina $<60 \mathrm{ml} / \mathrm{min}$, de $13,3 \%$. A incidência de NIC

\footnotetext{
1 Physician; resident in interventional cardiology at the Invasive Cardiology Service of the Instituto Dante Pazzanese de Cardiologia, São Paulo, SP, Brazil

2 Physician; interventional cardiologist at Hospital São Lucas, Aracaju, SE, Brazil

${ }^{3}$ Ph.D. physician; interventional cardiologist at the Invasive Cardiology Service of Instituto Dante Pazzanese de Cardiologia, São Paulo, SP, Brazil ${ }^{4}$ Associate professor and Director of the Invasive Cardiology Service of the Instituto Dante Pazzanese de Cardiologia, São Paulo, SP, Brazil ${ }^{5}$ Physician; resident in interventional cardiology at the Invasive Cardiology Service of the Instituto Dante Pazzanese de Cardiologia, São Paulo, SP, Brazil

${ }^{6}$ Physician; interventional cardiologist at Invasive Cardiology Service of the Instituto Dante Pazzanese de Cardiologia, São Paulo, SP, Brazil ${ }^{7}$ Physician; interventional cardiologist at the Invasive Cardiology Service of the Instituto Dante Pazzanese de Cardiologia, São Paulo, SP, Brazil ${ }^{8}$ Physician; interventional cardiologist at the Invasive Cardiology Service of the Instituto Dante Pazzanese de Cardiologia, São Paulo, SP, Brazil
}

\footnotetext{
9 Physician; interventional cardiologist at the Invasive Cardiology Service of the Instituto Dante Pazzanese de Cardiologia, São Paulo, SP, Brazil

${ }^{10}$ Physician; interventional cardiologist at the Invasive Cardiology Service of the Instituto Dante Pazzanese de Cardiologia, São Paulo, SP, Brazil 11 Ph.D. Physician; interventional cardiologist at the Invasive Cardiology Unit of the Instituto Dante Pazzanese de Cardiologia, São Paulo, SP, Brazi 12 Associate Professor and General Director of the Instituto Dante Pazzanese de Cardiologia, São Paulo, SP, Brazil

${ }_{13}$ Associate Professor and Director of the Centre of Interventions in Structural Heart Diseases of the Instituto Dante Pazzanese de Cardiologia, São Paulo, SP, Brazil
}

Correspondence to: Mauricio Sales de Oliveira. Av. Dr. Dante Pazzanese, 500 Vila Mariana São Paulo, SP, Brasil CEP 04012909

E-mail: mso01@uol.com.br

Received on: 7/3/2012 • Accepted on: 9/10/2012 
patients with renal dysfunction $(P=0.93)$. Conclusions: The use of a maximal preload dose of rosuvastatin did not have a protective effect on renal function in chronic statin users undergoing elective $\mathrm{PCI}$.

DESCRIPTORS: Angioplasty. Contrast media. Statins. Creatinine. Kidney diseases.

C ontrast-induced nephropathy $(\mathrm{CIN})$ is a potential complication of percutaneous coronary intervention (PCI). CIN is the third leading cause of in-hospital acute renal failure, occurring in approximately $7 \%$ of patients exposed to iodinated contrast agents, and usually presents spontaneous resolution. ${ }^{1,2}$ However, CIN may be associated with a longer hospital stay, increased morbidity and mortality, and higher hospitalisation costs, especially in those patients who require renal replacement therapy. ${ }^{3}$

The pathogenesis of $\mathrm{CIN}$ is not well understood but has been linked to inflammation, endothelial dysfunction, and oxidative stress. ${ }^{4}$ Pre-existing kidney disease, diabetes mellitus, left ventricular dysfunction, advanced age, and the use of large amounts of iodinated contrast are all major risk factors for $\mathrm{CIN} .5,6$

Statins are widely used in clinical practice for their cholesterol-lowering effects, especially in patients with atherosclerotic disease. The effects of statins, however, extend beyond cholesterol reduction and include improved endothelial function and potential anti-inflammatory and anti-oxidative effects. ${ }^{7}$

Short-term pre-treatment with statins is associated with favourable outcomes in various clinical scenarios, such as the prevention of peri- $\mathrm{PCl}$ myocardial injury or atrial fibrillation after cardiac surgery. Recent studies have suggested that the pre- $\mathrm{PCl}$ administration of statins can also prevent the occurrence of $\mathrm{CIN} .{ }^{8}$

The present study sought to evaluate the effects of a preload dose of rosuvastatin prior to elective $\mathrm{PCl}$ in patients receiving chronic statin treatment.

\section{METHODS}

This prospective, randomised, open, single-centre study included patients with coronary artery disease who were referred for the elective percutaneous implantation of at least one stent.

Those patients diagnosed with acute coronary syndrome for $<30$ days, restenotic lesions, or lesions in venous or arterial grafts were excluded. foi de $8,1 \%$ e não mostrou diferença entre os grupos $(9 \%$ vs. $7,4 \%$; $P=0,89)$. A incidência de NIC nos diabéticos foi de $15 \%$ vs. $13,6 \%(P=0,75)$ e nos portadores de disfunção renal prévia foi de $12,5 \%$ vs. $0(P=0,93)$. Conclusões: $\mathrm{O}$ uso de uma dose de reforço de rosuvastatina em sua posologia máxima não exerceu efeito protetor renal nos pacientes em uso crônico de estatina submetidos a ICP eletiva.

DESCRITORES: Angioplastia. Meios de contraste. Estatinas. Creatinina. Nefropatias.

All patients included in this analysis had been receiving statin treatment for at least 30 days. After signing the informed consent, the patients were divided into two groups: those patients who would (group 1) and those who would not (group 2) receive a maximal dose of rosuvastatin $(40 \mathrm{mg})$ two to six hours before the $\mathrm{PCl}$.

Blood samples were collected from both groups to analyse serum creatinine levels before and 24 hours after the procedure. Creatinine clearance was also evaluated before and after the procedure using the formula developed by Cockcroft \& Gault. Those with a pre-PCI creatinine clearance $<60 \mathrm{~mL} / \mathrm{min}$ received intravenous hydration $(0.9 \%$ saline, $1 \mathrm{~mL} / \mathrm{kg} /$ hour in the case of normal left ventricular function or $0.5 \mathrm{~mL} / \mathrm{kg} /$ hour in the case of left ventricular dysfunction) for at least six hours before and 12 hours after $\mathrm{PCl}$, according to the institution's protocol.

\section{Study objectives and definitions}

The CIN frequency, variations in creatinine levels (pre-and post- $\mathrm{Cr}$ ) and creatinine clearance rates (pre-and post- $\mathrm{CrCl}$ ), and percentage variation in creatinine clearance of the two groups were compared. The subgroups containing diabetic patients with renal dysfunction were also evaluated.

$\mathrm{CIN}$ was defined as an absolute increase in the serum creatinine level to $\geq 0.5 \mathrm{mg} / \mathrm{dL}$ or a $\geq 25 \%$ increase in the creatinine level in 24 hours. ${ }^{5,9}$

\section{Statistical analysis}

The categorical data are shown as absolute numbers and percentages, and the continuous data are shown as the means \pm standard deviation. The categorical variables were compared using the chi-squared test or Fisher's exact test. The continuous variables were compared with the Student's $t$-test (paired and non-paired). The Mann-Whitney $U$ test was used for the non-parametric variables. A two-tailed P-value of $<0.05$ was considered to be statistically significant. The Statistical Package for Social Sciences (SPSS - Chicago, USA), release 13, was used for all analyses. 


\section{RESULTS}

One hundred thirty-five patients undergoing elective $\mathrm{PCl}$ at the Instituto Dante Pazzanese de Cardiologia (Sao Paulo, SP, Brazil) between June of 2010 and May of 2011 who met the study inclusion criteria were randomised to group $1(n=67)$ or group $2(n=68)$.

The mean age of the patients was $60.7 \pm 9.3$ years. The prevalence of diabetes was $31.1 \%(n=42)$. The prevalence of pre-existing renal dysfunction (i.e., those patients with creatinine clearance values $<60 \mathrm{~mL} / \mathrm{min}$ ) was $13.3 \%(n=18)$. The mean volume of contrast used per procedure was $75.5 \pm 32.1 \mathrm{~mL}$.

Table 1 shows the demographic and procedural variables for both of the groups. With the exception of gender, with females being more prevalent in group 1, no significant differences were observed between the two groups.

The incidence of $\mathrm{CIN}$ in the entire study population was $8.1 \%$ and did not differ between the two groups (9\% in group $1 \mathrm{vs} .7 .4 \%$ in group $2, \mathrm{P}=0.89$ ).

The variations in serum creatinine levels (pre- $\mathrm{PCl}$ vs. post- $\mathrm{PCl}$ ) were negative, indicating increased creatinine values after the $\mathrm{PCl}$ procedure (group 1, mean of -0.239 $\mathrm{mg} / \mathrm{dL}$, ranging from -0.057 to +0.009 ; group 2 , mean of $-0.0098 \mathrm{mg} / \mathrm{dL}$, ranging from -0.048 to +0.028 ; $\mathrm{P}=0.71)$. The variations in creatinine clearance levels (pre- $\mathrm{PCl}$ vs. post- $\mathrm{PCl}$ ) were also negative, confirming the worsening of renal function after $\mathrm{PCl}$ (group 1, mean of $-2.71 \mathrm{~mL} / \mathrm{min} / 1.73 \mathrm{~m}^{2}$, ranging from -5.76 to +0.23 ; group 2, mean of $-1.10 \mathrm{~mL} / \mathrm{min} / 1.73 \mathrm{~m}^{2}$, ranging from -4.72 to $+2.51 ; P=0.54)$. The analysis of the percentage change in creatinine clearance indicated that the values for group 1 and group 2 were both close to 1 , as the variation in pre- and post-procedure creatinine clearance values was very small (group 1, mean post- $\mathrm{CrCl} /$ pre- $\mathrm{CrCl}=0.98$, group 2, mean post- $\mathrm{CrCl} /$ pre- $\mathrm{CrCl}=1.00 ; \mathrm{P}=0.59$ ). These data are shown in summarised form in Table 2.

The figure shows the presence of individual variation in serum creatinine and creatinine clearance before and after $\mathrm{PCl}$ in both groups.

The diabetics (31.1\% of the study population) were equally distributed between the two groups (29.9\% vs. $32.4 \%$ for groups 1 and 2 , respectively, $\mathrm{P}=0.89$ ). The overall incidence of CIN was $14.2 \%$ and did not differ

TABLE 1

Distribution of demographic procedural variables by group

\begin{tabular}{|c|c|c|c|}
\hline Variables & $\begin{array}{l}\text { Group } 1 \\
(n=67)\end{array}$ & $\begin{array}{r}\text { Group } 2 \\
(n=68)\end{array}$ & $\mathbf{p}$ \\
\hline Age, years (mean + SD) & $59.4 \pm 8.6$ & $62.2 \pm 9.8$ & 0.08 \\
\hline Female, n (\%) & $29(43.3)$ & $16(23.5)$ & 0.01 \\
\hline Diabetes, n (\%) & $20(29.9)$ & $22(32.4)$ & 0.75 \\
\hline Smoking, n (\%) & $14(20.8)$ & $17(25)$ & 0.57 \\
\hline Dyslipidaemia, n (\%) & $49(73.1)$ & $53(77.9)$ & 0.52 \\
\hline Access route, n (\%) & & & 0.67 \\
\hline Radial & $38(56.7)$ & $41(60.3)$ & \\
\hline Femoral & $29(43.3)$ & $27(39.7)$ & \\
\hline Contrast volume, $\mathrm{mL}$ & 72.2 & 78.2 & 0.35 \\
\hline Type of contrast, n (\%) & & & $>0.99$ \\
\hline High osmolarity & $27(40.3)$ & $27(39.7)$ & \\
\hline Low osmolarity & $40(59.7)$ & $41(60.3)$ & \\
\hline \multicolumn{4}{|l|}{ Serum cr, mg/dl } \\
\hline Pre-PCl & $0.89 \pm 0.24$ & $0.98 \pm 0.21$ & 0.02 \\
\hline Post-PCI & $0.91 \pm 0.26^{*}$ & $0.99 \pm 0.24^{+}$ & 0.06 \\
\hline \multicolumn{4}{|l|}{$\mathrm{CrCl}, \mathrm{mL} / \mathrm{min} / 1.73 \mathrm{~m}^{2}$} \\
\hline Pre & $96.1 \pm 31.3$ & $87.5 \pm 32.2$ & 0.15 \\
\hline Post & $93.4 \pm 29.8^{\ddagger}$ & $86.4 \pm 29.7^{\S}$ & 0.06 \\
\hline
\end{tabular}


TABLE 2

Changes in serum creatinine levels (pre-Cr/post-Cr), creatinine clearance rates (post- $\mathrm{CrCl} / \mathrm{pre}-\mathrm{CrCl}$ ), and creatinine clearance ratios (post- $\mathrm{CrCl} /$ pre- $\mathrm{CrCl}$ ) in both groups

\begin{tabular}{lccc}
\hline & Group $\mathbf{1}(\mathbf{n}=\mathbf{6 7})$ & Group 2 $(\mathbf{n}=\mathbf{6 8})$ & $\mathbf{P}$ \\
\hline$\Delta \mathrm{CR}, \mathrm{mg} / \mathrm{dL}$ & $-0.239[-0.057$ to +0.009$]$ & $-0.0098[-0.048$ to +0.028$]$ & 0.71 \\
$\Delta \mathrm{CrCl}, \mathrm{mL} / \mathrm{min} / 1.73 \mathrm{~m}^{2}$ & $-2.71[-5.76$ to +0.23$]$ & $-1.10[-4.72$ to +2.51$]$ & 0.54 \\
$\mathrm{Post}-\mathrm{PCl} \mathrm{CrCl} / \mathrm{pre}-\mathrm{PCl} \mathrm{CrCl}$ & $0.98[0.94$ to 1.01$]$ & $1.00[0.96$ to 1.05$]$ & 0.59 \\
\hline
\end{tabular}

$\Delta=$ variation, $\mathrm{CrCl}=$ creatinine clearance, $\mathrm{Cr}=$ creatinine

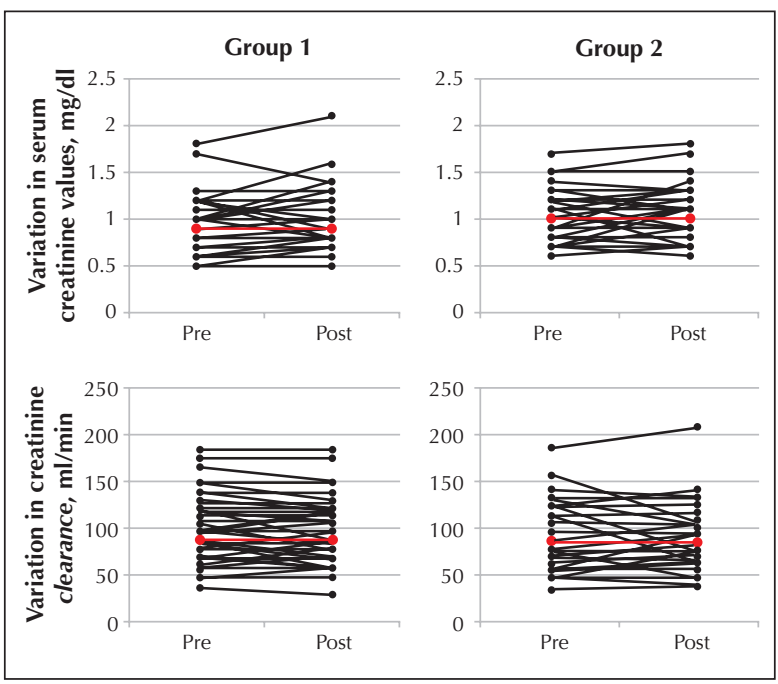

Figure - Variation in serum creatinine levels and creatinine clearance rates for each patient included in the study. The graphs on the left illustrate the variation among the patients who received a booster dose of rosuvastatin, and the graphs on the right show data from the control group.

between the two groups (15\% vs. $13.6 \%$ for groups 1 and 2 , respectively, $\mathrm{P}=0.75)$. The evaluation of the variation in serum creatinine levels and creatinine clearance rates also indicated a slight worsening of renal function in the diabetic subgroup, with no statistical significance for either group (Table 3).

The patients with renal dysfunction $(13.3 \%$ of the studied population) were equally distributed between the two groups $(11.9 \%$ vs. $14.7 \%$ for groups 1 and 2, respectively; $\mathrm{P}=0.82$ ), and the incidence of $\mathrm{CIN}$ in these patients was $5.6 \%$, with no difference between the two groups $(12.5 \%$ vs. $0 \%$ for groups 1 and 2 , respectively; $\mathrm{P}=0.93)$. The serum creatinine and creatinine clearance evaluation showed positive variances and a discreet improvement in renal function in both groups; however, these values were not statistically significant (Table 4).

\section{DISCUSSION}

The incidence of CIN in the population of patients on chronic statin use undergoing elective $\mathrm{PCI}$ was $8.1 \%$.
A maximal booster dose $(40 \mathrm{mg})$ of a powerful nextgeneration statin (rosuvastatin) provided two to six hours before the procedure failed to prevent the occurrence of CIN. This observation extends to the subgroups of patients with diabetes and renal dysfunction.

Several pathological mechanisms have been linked to $\mathrm{CIN}$. The contrast medium stimulates the macula densa of the kidneys to produce adenosine, release angiotensin, vasopressin and endothelin, and decrease the synthesis of nitric oxide, causing hypoxia in the renal medulla. Later, other renal injury mechanisms, such as oxidative stress, the release of inflammatory cytokines, and complement activation promote the development of cellular lesions (cytoplasmic vacuolisation), necrosis, interstitial inflammation, and tubular obstruction. Statins may act during these stages to downregulate the angiotensin receptor, decrease endothelin synthesis, increase nitric oxide bioavailability, decrease the expression of endothelial adhesion molecules, limit the production of oxygen reactive species, and protect against complement-mediated injury. ${ }^{8}$

A booster dose of rosuvastatin was administered two to six hours before the procedure to ensure that tissues were exposed to contrast medium during the peak serum concentration of rosuvastatin, which occurs approximately five hours after administration. Some anti-inflammatory effects were detected in the first 24 hours after the administration of a single $40 \mathrm{mg}$ dose of pravastatin. ${ }^{10}$

This and other studies evaluating the role of statins in CIN prevention have yielded different and sometimes contradictory results. However, it is necessary to understand the different methodologies and the different study populations.

For instance, in the Atorvastatin for Reduction of Myocardial Damage during Angioplasty-Contrast-Induced Nephropathy (ARMyDACIN) study, the administration of a high dose of atorvastatin (80 mg 40 hours before and $12 \mathrm{mg}$ two hours before the procedure) reduced the incidence of $\mathrm{CIN}$ in the treatment group compared to the placebo group (5\% vs. $13.2 \%, \mathrm{P}=0.046){ }^{8}$

However, two important considerations must be made when comparing the results of the ARMyDACIN study with this analysis: 1) the patients included in the 
TABLE 3

Variations in serum creatinine levels (pre-Cr/post-Cr), creatinine clearance rates (post-CrCl/pre-CrCl), and creatinine clearance ratios (post- $\mathrm{CrCl} /$ pre- $\mathrm{CrCl}$ ) in diabetic patients

\begin{tabular}{llll}
\hline & Group 1 & Group 2 & P \\
\hline$\Delta \mathrm{CR}, \mathrm{mg} / \mathrm{dL}$ & $-0.02[-0.09$ to +0.04$]$ & $-0.05[-0.12$ to +0.02$]$ & 0.48 \\
$\Delta \mathrm{CrCl}, \mathrm{mL} / \mathrm{min} / 1.73 \mathrm{~m}^{2}$ & $-2.39[-9.03$ to +4.25$]$ & $-5.09[-12.31$ to +2.11$]$ & 0.53 \\
Post-PCl CrCl $/ \mathrm{pre}-\mathrm{PCl} \mathrm{CrCl}$ & $0.98[0.91$ to 1.05$]$ & $0.97[0.89$ to 1.04$]$ & 0.61 \\
\hline$\Delta=$ variation, $\mathrm{CrCl}=$ creatinine clearance, $\mathrm{Cr}=$ creatinine & & \\
\hline
\end{tabular}

TABLE 4

Variations in serum creatinine levels (pre-Cr/post-Cr), creatinine clearance rates (post- $\mathrm{CrCl} / \mathrm{pre}-\mathrm{CrCl}$ ), and creatinine clearance ratios (post- $\mathrm{CrCl} / \mathrm{pre}-\mathrm{CrCl}$ ) in patients with previous kidney disease

\begin{tabular}{llll}
\hline & Group 1 & Group 2 & P \\
\hline$\Delta \mathrm{CR}, \mathrm{mg} / \mathrm{dL}$ & $+0.02[-0.14$ to +0.19$]$ & $+0.11[-0.05$ to +0.28$]$ & 0.63 \\
$\Delta \mathrm{CrCl}, \mathrm{mL} / \mathrm{min} / 1.73 \mathrm{~m}^{2}$ & $+2.24[-2.9$ to +7.4$]$ & $+9.8[-1.6$ to +21.3$]$ & 0.56 \\
Post- $\mathrm{PCl} \mathrm{CrCl} / \mathrm{pre}-\mathrm{PCl} \mathrm{CrCl}$ & $1.03[0.91$ to 1.14$]$ & $1.18[0.97$ to 1.39$]$ & 0.50 \\
\hline$\Delta=$ variation, $\mathrm{CrCl}=$ creatinine clearance, $\mathrm{Cr}=$ creatinine & & \\
\hline
\end{tabular}

ARMyDACIN study were not receiving any statins, 2) the study only included patients experiencing an acute coronary syndrome. In contrast, the population of the present study was already receiving chronic statin treatment and was, therefore, experiencing the pleiotropic effects of this agent. Furthermore, the patients in the present series had stable or stabilised coronary disease, unlike ARMyDACIN, in which the patients with acute coronary disease, with an enhanced inflammatory profile and associated endothelial dysfunction, may have reaped greater benefits from the anti-inflammatory and antioxidant effects of statins.

In 2011, Zhang et al. ${ }^{4}$ published a meta-analysis that included six registries and six randomised studies evaluating the chronic use of statins and the incidence of CIN. While four of the registries showed a nephroprotective role of statins, the randomised studies showed no statistically significant association between the use of high doses of statins for a short period and the occurrence of CIN (relative risk [RR] 0.70, 95\% confidence interval $[95 \% \mathrm{Cl}]: 0.48$ to 1.02$)$, despite noticeable trend toward reduction in those receiving treatment.

Another meta-analysis published in 2011 investigated eight randomised trials with patients who were or were not receiving chronic low-dose statin treatment, finding that pre-treatment with high doses of these drugs reduced the incidence of $\mathrm{CIN}$ in patients with normal pre- $\mathrm{PCl}$ renal function (RR $0.51 ; 95 \% \mathrm{Cl}: 0.34-0.77 ; \mathrm{P}$
$=0.001)$, but did not change the outcome for patients with previous renal dysfunction (RR 0.90; $95 \% \mathrm{Cl}$ : $0.49-1.65 ; \mathrm{P}=0.73){ }^{11}$

Finally, the fact that a slight improvement was observed in the renal function of patients with previous renal dysfunction (creatinine clearance $<60 \mathrm{~mL} / \mathrm{min}$ ), regardless of prior administration of rosuvastatin, deserves a brief comment. Although this study was not designed for this purpose, it is believed that this finding arose partly because this select group of patients received intravenous hydration before and after $\mathrm{PCl}$, confirming the important role of hydration in the prevention of CIN.

\section{Study limitations}

A potential limitation of this study is the short post- $\mathrm{PCl}$ time interval during which serum creatinine levels were measured. While the studies evaluating CIN have shown that the peak increase in creatinine occurs between 48 and 72 hours after exposure to contrast medium, the measurement in this study was obtained 24 hours after PCl. However, this early assessment of renal function does not invalidate the study, as patients exhibiting serum creatinine increases of $<0.5 \mathrm{mg} / \mathrm{dL}$ in the first 24 hours after exposure to contrast medium have a low probability of developing $\mathrm{CIN} .^{12}$

Another possible limitation is the interval between the administration of rosuvastatin and the $\mathrm{PCl}$ procedure. 
Although the pharmacokinetics of this drug indicate a peak serum concentration during the first hours after administration, it is possible that the pleiotropic effects of rosuvastatin may not occur until a later time point.

\section{CONCLUSIONS}

The administration of a maximal (40 mg) booster dose of rosuvastatin to patients receiving chronic statin treatment has no renal protective effect during elective coronary angioplasty.

\section{ACKNOWLEDGMENT}

The authors would like to thank the radiology technician Marcelo de Oliveira Quirino for his technical support in this work.

\section{CONFLICTS OF INTEREST}

The authors declare no conflicts of interest.

\section{REFERENCES}

1. Nash K, Hafeez A, Hou S. Hospital-acquired renal insufficiency. Am J Kidney Dis. 2002;39(5):930-6.

2. McCullough PA. Contrast-induced acute kidney injury. J Am Coll Cardiol. 2008;51(15):1419-28.

3. McCullough PA, Adam A, Becker CR, Davidson C, Lameire $N$, Stacul $F$, et al. Epidemiology and prognostic implications of contrast-induced nephropathy. Am J Cardiol. 2006; 98(6A): $5 \mathrm{~K}-13 \mathrm{~K}$.
4. Zhang T, Shen LH, Hu LH, He B. Statins for the prevention of contrast-induced nephropathy: a systematic review and meta-analysis. Am J Nephrol. 2011;33(4):344-51.

5. Rihal CS, Textor SC, Grill DE, Berger PB, Ting HH, Best PJ, et al. Incidence and prognostic importance of acute renal failure after percutaneous coronary intervention. Circulation. 2002;105(19):2259-64.

6. Sudarsky D, Nikolsky E. Contrast-induced nephropathy in interventional cardiology. Int J Nephrol Renovasc Dis. 2011; 4:85-99.

7. Farmer JA. Pleiotropic effects of statins. Curr Atheroscler Rep. 2000;2(3):208-17.

8. Patti G, Ricottini E, Nusca A, Colonna G, Pasceri V, D'Ambrosio A, et al. Short-term, high-dose Atorvastatin pretreatment to prevent contrast-induced nephropathy in patients with acute coronary syndromes undergoing percutaneous coronary intervention (from the ARMYDA-CIN [atorvastatin for reduction of myocardial damage during angioplasty-contrast-induced nephropathy] trial. Am J Cardiol. 2011;108(1):1-7.

9. Solomon RJ, Natarajan MK, Doucet S, Sharma SK, Staniloae CS, Katholi RE, et al. Cardiac Angiography in Renally Impaired Patients (CARE) study: a randomized double-blind trial of contrast-induced nephropathy in patients with chronic kidney disease. Circulation. 2007;115(25):3189-96.

10. Wassmann S, Faul A, Hennen B, Scheller B, Böhm M, Nickenig G. Rapid effect of 3-hydroxy-3-methylglutaryl coenzyme a reductase inhibition on coronary endothelial function. Circ Res. 2003;93(9):e98-103.

11. Zhang BC, Li WM, Xu YW. High-dose statin pretreatment for the prevention of contrast-induced nephropathy: a metaanalysis. Can J Cardiol. 2011;27(6):851-8.

12. Guitterez NV, Diaz A, Timmis GC, O'Neill WW, Stevens MA, Sandberg KR, et al. Determinants of serum creatinine trajectory in acute contrast nephropathy. J Interv Cardiol. 2002; 15(5):349-54. 